\section{The injustice of}

\section{pre-authorization}

I agree with Dr. Nasrallah's clear description of the malign nature of the pre-authorization system, as described in his editorial "Pre-authorization is illegal, unethical, and adversely disrupts patient care" (From the Editor, CURRENT PSYCHIATRY. April 2020, p. 5,10-11). The doctor's job is not to improve the bottom line of insurance companies by tailoring medication choices based on cost or pill quantity.

As an example of the latter, I was recently told by a pharmacist that I needed to call the insurer to justify why a patient was going from a prescription for \#30 citalopram to \#45 citalopram. The request had triggered a quantity limit. The pharmacist had explained to the insurer that more pills were required because the dosage was being lowered from 40 to $30 \mathrm{mg} / \mathrm{d}$. Because there are no $30-\mathrm{mg}$ tablets available, it made most sense for the patient to take one and a half 20-mg tablets, which totals 45 pills per month.

The insurer-probably a screener, not a pharmacist—would not accept that explanation and insisted that I call them myself. I bitterly resented how casually the insurer expected busy doctors to interrupt their clinical work to comply with arbitrary micromanagement of pill quantities! I've seldom

\section{Keep in touch! letters@currentpsychiatry.com} OR

Comments \& Controversies CURRENT PsychIATRY

7 Century Drive, Suite 302 Parsippany, NJ 07054

All letters are subject to editing. seen such nonsense in more than 40 years of practice.

When doctors call these insurers, they are connected to a screener, but never a pharmacist. The screener asks a series of questions prompted by a computer. We give them verbal answers, but they don't comprehend what they input into their system. The reasons we give to the screener may not even make it into the report that the screener passes on to the staff member who makes the decision. The doctor is not told what is in the report, or who is reviewing it. So much for transparency in this era that supposedly values it!

In any case, answering all the computer-prompted questions can take a long time. And time, as we know (but they do not), is not elastic.

Serious consequences may ensue if an insurer denies coverage for the doctor's first choice. Many patients cannot afford to pay hundreds of extra dollars out of pocket. The insurer may ask the doctor to choose a different medication. Aside from the disrespect for the doctor's decision implied by such a request, another problem is that the patient knows the new medication is his/her doctor's second (or third) choice. Any positive placebo effect that may have existed before has now been lost. Most doctors would be glad to have a positive placebo effect augmenting the physiologic effects of the medication, especially when the patient is already feeling helpless or hopeless. These negative feelings would likely increase when the patient feels pressured into starting a medication that they know was their doctor's second choice.

These are just a few reasons preauthorization is a horrid system; Dr. Nasrallah covered many others in

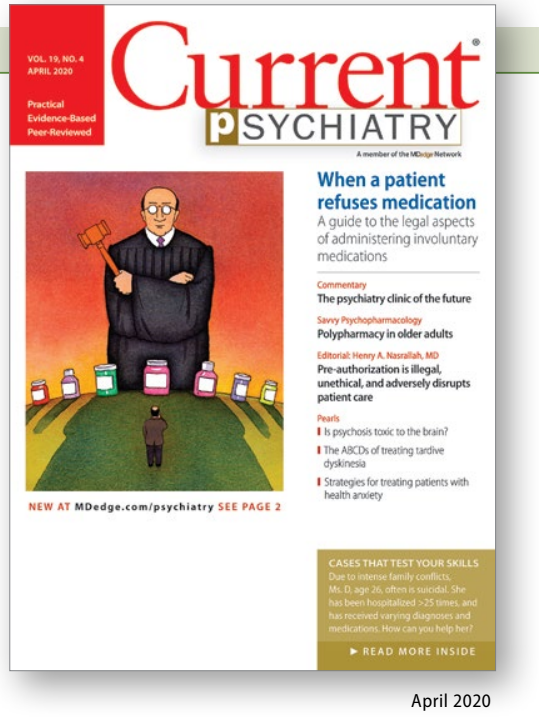

his editorial. The system, as currently structured, needs to be eliminated.

Arthur Mode, MD Private psychiatric practice Falls Church, Virginia

Disclosure: The author reports no financial relationships with any companies whose products are mentioned in this article, or with manufacturers of competing products.

Hooray for Dr. Nasrallah's editorial about pre-authorization! I worry, however, that he missed some important considerations.

He writes, "The welfare of the patient is not on the insurance company's radar screen, perhaps because it is crowded out by dollar signs." But the welfare of the patient is exactly what is on their radar screens! If the patient dies, the insurance company profits, because it will not have to pay for treatment. This is like having a Red Sox employee manage the Yankees, except we are talking about human lives, not baseball games. Dr. Nasrallah asks (but does not answer), "How did for-profit insurance companies empower themselves to tyrannize clinical practice so that the treatment administered isn't customized to the patient's need but instead to fatten the profits of the insurance company?" The answer: Physicians let them. Many physicians are paid by insurers directly or through work for clinics or hospitals. He who pays the piper calls the tune. 
And because employers often select the insurer, patients have no say.

Honesty is most important. Preauthorization is a dishonest term, because pre-authorization actually is pre-denial. The term pre-authorization should be replaced by "predenial." It is also fraudulent when insurance companies call themselves health care companies, because they only provide insurance, not health care. Similarly, the term "evidencebased medicine" is typically only an excuse that insurers use to refuse to cover the cost of treatment. In another scenario of Dr. Nasrallah's patient with treatment-resistant depression who responded to modafinil, what if the evidence for using this medication was based on the patient's psychiatric history alone, without any evidence from a meta-analysis of randomized controlled trials? That would not be "evidence-based" in the dishonest world of insurance. Evidence to insurers does not include what is evident in the patient's response to a given treatment.

What about amnesty, especially for physicians who work in the so-called pre-authorization denial business? Some even claim to be peers (ie, the "peer to peer reviews" they conduct) and insist they cannot be on speakerphone, so that their identity is kept secret from the patient. Not all of these "physicians" are incompetent. Not all of them have criminal minds or lack empathy. Some may have had exceptional circumstances leading them to such a profession, which Dr. Nasrallah correctly notes as felonious behavior. For these physicians, I think some kind of amnesty program would be appropriate, rather than prosecution.

John Jacobs, MD

Private psychiatric practice Manchester, New Hampshire
Disclosure: The author reports no financial relationships with any companies whose products are mentioned in this article, or with manufacturers of competing products.

I have just finished reading Dr. Nasrallah's editorial about preauthorization. I agree with everything he said, but I do have a couple of comments:

1. Many of our colleagues do not accept insurance because their practices operate on a cash basis. This seems to obviate the problem of preauthorization, and suggests that if we truly want to get rid of pre-authorization, we should get rid of insurance.

2. In practices that do not accept insurance, some patients may be filing their own insurance claims. Do you have any information on this approach? Are patients able to apply pressure to their insurance companies? Do patients get frustrated with their insurance companies and pay cash, rather than trying to negotiate with their insurance companies?

Katherine Hankins, MD Private psychiatric practice Omaha, Nebraska

Disclosure: The author reports no financial relationships with any companies whose products are mentioned in this article, or with manufacturers of competing products.

Why not address the underlying (and actual) cause of the "pre-authorization" scam/scandal: the private health insurance industry.

Other countries in the western world have figured out how to provide guaranteed health care to their citizens without resorting to a costly insurance industry. This parasitic business suborns $10 \%$ to $20 \%$ of the health care bill while wasting our money on withholding health care deemed "not eligible" for patients who need it. Meanwhile, the executives who manage this insurance racket are paid enormous salaries not to deliver services.
Moreover, we reap a double loss to the health care system because hospitals must employ a building full of clerks to submit (and then, when rejected, re-submit) bills for reimbursement of hospital charges.

Franz Kafka would immediately grasp the despicable workings of this self-serving scheme.

David Link, MD Associate Professor of Pediatrics Harvard Medical School Boston, Massachusetts

Disclosure: The author reports no financial relationships with any companies whose products are mentioned in this article, or with manufacturers of competing products.

\section{Dr. Nasrallah responds}

Thanks to all my colleagues who commented on (and unanimously agreed with) my editorial. It is clearly one of the most outrageous hurdles that all psychiatric practitioners face every day.

For the sake of our patients who deserve optimal medical care (laboratory tests, procedures, and medications), insurance companies must be tightly regulated to avoid second-guessing the treating clinicians, and readily cover what is prescribed. Some patients who can afford it resort to paying out of pocket for privacy reasons or for rapid access to psychiatric care, and may or may not file for insurance coverage, but they will certainly receive what their psychiatrist deems appropriate after a direct evaluation.

I hope the American Psychiatric Association and American Medical Association will continue to forcefully pursue legislation to eliminate pre-authorization and restore some sanity to the critical process of good clinical care.

Henry A. Nasrallah, MD Professor of Psychiatry, Neurology, and Neuroscience

Medical Director: Neuropsychiatry Director, Schizophrenia and Neuropsychiatry Programs

University of Cincinnati College of Medicine Cincinnati, Ohio

Professor Emeritus, Saint Louis University St. Louis, Missouri 